motor-cars. And then we wonder why our mechanical superiority is being lost to other nations.

It is to be hoped that the Government will fail in passing the Bill. The numbering, registering, and examining of cardrivers with a maximum of 20 miles an hour are ridiculous while the publican and butcher-boy can race on main roads and dash round corners without let or hindrance. From a surgical point of view it would be interesting to know the percentage of accidents due to horses and to motor-cars in this country. We must hope that before long THE LANCET will go forward again as representing Progress rather than going back to the palæo-conservative frame of mind.

$$
\text { I am, Sirs, yours faithfully, }
$$

August 11th, 1903.

$$
\text { Medical Motorist. }
$$

P.S.-From a sanitary point of view there is no comparison between the mechanical and animal forms of traction. -M.M.

** The comparison between the amount of danger and dust caused by the four-in-hand and the motor-car or cycle breaks down. Everyone can see a four-in-hand approaching and can avoid it, while there are 500 or more motor vehicles on the road against one four-in-hand. We have no objection to motor-cars being used on the highroads so long as they are driven with some regard to the "palæo-conservative" methods of locomotion which still obtain.-ED. L.

\section{THE TERMINALS OF THE ARC LAMP.}

\section{To the Editors of THE LANCET.}

SIRS,-I have lately been making some experiments with the object of improving the arc lamp in use in the electrical department of St. Bartholomew's Hospital. My senior colleague in the department, Dr. H. L. Jones, suggested to me that the metal indium might possibly be useful as terminals for the arc. The spectrum of this metal, in addition to a brilliant bright line in the blue, shows a magnificent bright urple line near the end of the visible spectrum. As indium proved to be too soft a metal for the terminals of the lamp I thought that it might be possible to combine it with the iron electrodes. With this end in view I had the iron terminals bored with a hole in the centre running in the long axis of the iron from the apex to nearly the base. The holes were then filled with the metal indium which is soft enough to be drawn out into a wire. The arc produced between such terminals is of a gorgeous purple colour, but, unfortunately, owing to the comparatively low temperature at which indium volatilises, the holes in the iron electrodes were soon empty, after the lamp had been running for about 15 minutes. In addition to this $I$ found that indium was much too expensive, for hospital use at any rate. Two small patches of lupus treated with the indium-iron arc appeared to react very quickly, certainly much quicker than with iron only.

I next tried, at the suggestion of Mr. J. H. Gardiner, F.O.S. (assistant in Sir William Crookes's laboratory), an alloy of zinc and aluminium, this combination giving off rays of much shorter wave-length than iron. The arc light of this alloy is of a rich purple colour and shows many bright lines in the visible violet. 'The alloy, however, has the disadvantage of burning up rather quickly. The reaction produced on patches of lupus with the aluminium-zinc arc is certainly greater than with iron in the same time. I have lately been concentrating the light on the part under treatment with a quartz-calcite lens of short focus, kindly lent to me by Mr. J. W. Gifford of Chard and described by him at the last meeting of the British Association. This quartz-calcite combination brings all the ultra-violet radiation practically to the same focus. I think that the lens will be found very useful in treatment. It is possible that in the future the Hewitt mercury vapour lamp may be of great value as there is absolutely no red in its spectrum. Unfortunately at the present time these lamps are only made in glass, most of the ultra-violet radiation thus being unavailable for therapeutical purposes. If the lamp could be made in quartz or in glass with a quartz end and indium could be introduced into the lamp I think that it might be found very useful in the treatment of lupus. I have ventured to send this letter in the hope that it may be useful to other workers with the lamp.

I am, Sirs, yours faithfully,

August 8th, 1903.

HUGH WaLsham.
NOTES FROM INDIA.

(From our Special Correspondent.)

A Hospital Ship for Invalids from India.-The High Infantile Mortality in Bengal and Bombay. $-A$ Soheme for the Nursing of Europeans.--The Plague Elpidemic.The Cocaine-eating Fashron.

$1 \mathrm{~T}$ is proposed to fit up one of the transports next trooping season partly as a hospital ship to convey invalids to England. The ship will be fitted with 100 beds for serious cases and will make three trips, thus taking home a total of 300 during the season. Invalids who are able to take care of themselves will go by ordinary transport as usual. The facts that over 2000 men are invalided every year, that over 4000 are constantly sick, and that over 750 deaths occur among the British troops should be borne in mind by those who cavil at the additional troops to be placed in South Atrica for India's benefit. The available men are at present none too many for the numerous emergencies which might at any time arise, especially when it is considered how many places in India there are to garrison and that there is an obvious limit to depletion.

The high infantile mortality in Bombay and Bengal seems to have attracted the attention of their respective sanitary commissioners, as they both refer to it in their reports. In Bombay city this "massacre of innocents" is accompanied with a large mortality among women of child-bearing age. There is also a high rate of still-births. The infant mortality in the city of Ahmedabad is also brought to notice. In Bengal a sudden increase seems to have begun in 1899. In Calcutta the infant mortality is appalling and in no less than 62 per cent. of the town areas the deaths exceeded the births. The whole province shows the increase of deathrate but no explanation is given to account for it.

With regard to the provision of nurses for Europeans in India, to which I recently referred, it is reported that a scheme of a comprehensive nature under the auspices of Lady Curzon is being worked out at Simla. It is expected that the scheme will have Government support and that an organisation may be created for the supply of nurses in each province.

The plague reports of the week are not so assuring. The mortality has risen in the Bombay Presidency and the total deaths have increased from 1563 to 2087. Outside Bombay only about 500 deaths were reported. In the Punjab the weekly mortality has fallen to 118 and for the United Provinces not a single death was returned. The Punjab has suffered severely. From Oct. 1st last up to July 348,302 cases, with 213,716 deaths, were registered, as against 316,236 cases and 217,940 deaths in the corresponding period of last year. Assuming these figures to be accurate the case mortality works out at 61 per cent. This percentage is low and suggests that the ultimate results of the living cases were not accurately known.

The curious magisterial decision in Bombay concerning cocaine which I reported to you some time ago has, fortunately, on appeal, been reversed and cocaine is now held to be an intoxicating drug. Of late the use of it has become so common that every " pan" seller mixes it with his areca paste. After all, the matter was a legal quibble upon the definition of terms. The chief clause under discussion runs: "Intoxicating drugs inclade ganja, bhang, charas, and every preparation and admixture of the same and every intoxicating drink or substance prepared from hemp, grain, or other materials not included in the term liauor, but does not include opium." This decision is a very important one, as it will lead to the drug being placed under the Abkari department and the present large unfettered sale will be restricted to those who possess a licence. The great and widespread evil of cocaine-eating in India is not realised either by the public at home or officials in India and the sooner these restrictions are extended the better.

July 24 th.

\section{MANCHESTER.}

(FROM OUR OWN CORRESPONDENT.)

\section{"Criminal Negleot."}

SOME little time since three houses in a street in Ancoats collapsed and two little girls in bed at the time were killed. An inquest, which was twice adjourned, was concluded on July 30th. According to the evidence of $\mathbf{M r}$. 